\title{
$A P O E$ effect on Alzheimer's disease biomarkers in older adults with significant memory concern
}

\author{
Shannon L. Risacher ${ }^{\mathrm{a}, \mathrm{b}}$, Sungeun Kim ${ }^{\mathrm{a}, \mathrm{b}, \mathrm{c}}$, Kwangsik Nho ${ }^{\mathrm{a}, \mathrm{b}, \mathrm{c}}$, Tatiana Foroud ${ }^{\mathrm{b}, \mathrm{d}}$, Li Shen ${ }^{\mathrm{a}, \mathrm{b}, \mathrm{c}}$, \\ Ronald C. Petersen ${ }^{\mathrm{e}}$, Clifford R. Jack, Jr., ${ }^{\mathrm{f}}$, Laurel A. Beckett ${ }^{\mathrm{g}}$, Paul S. Aisen ${ }^{\mathrm{h}}$, Robert A. Koeppe ${ }^{\mathrm{i}}$, \\ William J. Jagust ${ }^{j}$, Leslie M. Shaw ${ }^{\mathrm{k}}$, John Q. Trojanowski ${ }^{\mathrm{k}}$, Michael W. Weiner, ${ }^{1, \mathrm{~m}}$, \\ Andrew J. Saykin ${ }^{\mathrm{a}, \mathrm{b}, \mathrm{c}, \mathrm{d}, *}$, for the Alzheimer's Disease Neuroimaging Initiative (ADNI) ${ }^{1}$ \\ ${ }^{a}$ Department of Radiology and Imaging Sciences, Center for Neuroimaging, Indiana University School of Medicine, Indianapolis, IN, USA \\ ${ }^{b}$ Indiana Alzheimer Disease Center, Indiana University School of Medicine, Indianapolis, IN, USA \\ ${ }^{c}$ Center for Computational Biology and Bioinformatics, Indiana University School of Medicine, Indianapolis, IN, USA \\ ${ }^{d}$ Department of Medical and Molecular Genetics, Indiana University School of Medicine, Indianapolis, IN, USA \\ ${ }^{e}$ Department of Neurology, Mayo Clinic, Rochester MN, USA \\ ${ }^{f}$ Department of Radiology, Mayo Clinic, Rochester MN, USA \\ ${ }^{g}$ Department of Public Health Sciences, Division of Biostatistics, University of California-Davis, Davis, CA, USA \\ ${ }^{h}$ Department of Neurology, University of California-San Diego, San Diego, CA, USA \\ ${ }^{i}$ Department of Radiology, University of Michigan, Ann Arbor, MI, USA \\ ${ }^{j}$ Department of Neurology, University of California-Berkeley, Berkeley, CA, USA \\ ${ }^{k}$ Department of Pathology and Laboratory Medicine, University of Pennsylvania School of Medicine, Philadelphia, PA, USA \\ ${ }^{l}$ Departments of Radiology, Medicine and Psychiatry, University of California-San Francisco, San Francisco, CA, USA \\ ${ }^{m}$ Department of Veterans Affairs Medical Center, San Francisco, CA, USA
}

Abstract

Introduction: This study assessed apolipoprotein E (APOE) $\varepsilon 4$ carrier status effects on Alzheimer's disease imaging and cerebrospinal fluid (CSF) biomarkers in cognitively normal older adults with significant memory concerns (SMC).

Methods: Cognitively normal, SMC, and early mild cognitive impairment participants from Alzheimer's Disease Neuroimaging Initiative were divided by APOE $\& 4$ carrier status. Diagnostic and $A P O E$ effects were evaluated with emphasis on SMC. Additional analyses in SMC evaluated the effect of the interaction between $A P O E$ and $\left[{ }^{18} \mathrm{~F}\right]$ Florbetapir amyloid positivity on CSF biomarkers.

Results: SMC $\varepsilon 4+$ showed greater amyloid deposition than SMC $\varepsilon 4-$, but no hypometabolism or medial temporal lobe (MTL) atrophy. SMC $\varepsilon 4+$ showed lower amyloid beta 1-42 and higher tau/ptau than $\varepsilon 4-$, which was most abnormal in $A P O E \varepsilon 4+$ and cerebral amyloid positive SMC.

Discussion: SMC APOE $\varepsilon 4+$ show abnormal changes in amyloid and tau biomarkers, but no hypometabolism or MTL neurodegeneration, reflecting the at-risk nature of the SMC group and the importance of $A P O E$ in mediating this risk.

(C) 2015 The Alzheimer's Association. Published by Elsevier Inc. All rights reserved.

Keywords: $\quad$ Significant memory concern; SMC; Subjective cognitive decline; SCD; Apolipoprotein E; APOE; Neuroimaging; $\left[{ }^{18}\right.$ F $]$ Florbetapir PET; $\left[{ }^{18}\right.$ F $]$ Fluorodeoxyglucose; FDG; PET; Structural magnetic resonance imaging (MRI); Cerebrospinal fluid; CSF; Alzheimer's Disease Neuroimaging Initiative; ADNI

\footnotetext{
${ }^{1}$ Data used in preparation of this article were obtained from the Alzheimer's Disease Neuroimaging Initiative (ADNI) database (adni. loni.usc.edu). As such, the investigators within the ADNI contributed to the design and implementation of ADNI and/or provided data but did not participate in analysis or writing of this report. A complete listing
}

of ADNI investigators can be found at: http://adni.loni.usc.edu/wpcontent/uploads/how_to_apply/ADNI_Acknowledgement_List.pdf.

*Corresponding author. Tel.: +1-317-963-7501; Fax: +1-317-9637547.

E-mail address: asaykin@iupui.edu 


\section{Introduction}

Alzheimer's disease (AD) is the most common agerelated neurodegenerative disease, affecting nearly 5.2 million older adults in the United States [1]. Many AD researchers believe that effective treatments for $\mathrm{AD}$ will require intervention early in the disease course, even before clinical symptoms [2]. Thus, a significant goal is to identify participants likely to progress to AD (i.e., "at-risk") before significant cognitive decline.

One group thought to be at risk is cognitively normal older adults with subjective reports of cognitive changes [2-4]. Recently, an international consortium defined this group as subjective cognitive decline (SCD) [3]. In the Alzheimer's Disease Neuroimaging Initiative (ADNI), a comparable group of older adults were recruited with significant memory concerns (SMC) in the form of self-only complaints exceeding a predefined cut-off score on memory ratings. Previous studies have shown that older adults with $\mathrm{SCD} / \mathrm{SMC}$ have an increased risk for future progression to AD [5-16] and $\mathrm{AD}$-like changes in neuroimaging and cerebrospinal fluid (CSF) biomarkers [4,13,17-27]. In addition, SCD/SMC participants who are carriers of the most commonly reported genetic variant associated with late onset $\mathrm{AD}$, the apolipoprotein $\mathrm{E}(A P O E)$ \&4 allele, show greater medial temporal lobe (MTL) hypometabolism and atrophy, increased cerebral amyloid, and altered CSF measures of amyloid and tau $[22,23,28,29]$. However, to date, no studies have looked at the role of $A P O E$ \& 4 status in SCD/SMC across a comprehensive multimodal panel of major imaging and CSF AD biomarkers. Evaluating multiple biomarkers in the same cohort will help to define the staging of the SCD/SMC participants in relation to the Jack et al. (2013) model [30] and help determine the implication of APOE genotype for key AD pathophysiological processes, including amyloid deposition, tau hyperphosphorylation, and brain atrophy, in this important at-risk group.

We recently reported on the role of $A P O E \varepsilon 4$ carrier status on several multimodal biomarkers in early mild cognitive impairment (EMCI) participants and demonstrated a significant association between carrying an APOE 84 allele and amyloid pathology in both cognitively normal $(\mathrm{CN})$ older adults without complaints and EMCI participants [31]. However, the effect of $A P O E \& 4$ carrier status was minimal on CSF tau levels and brain atrophy. Thus, we sought to evaluate a similar question in SCD/SMC participants, as they are cognitively normal and thus less clinically affected than EMCI participants, but are at risk for AD due to subjective memory changes. We now also include $\left[{ }^{18} \mathrm{~F}\right]$ fluorodeoxyglucose (FDG) positron emission tomography (PET) for these groups and an expanded sample.

The goal of the present study was to evaluate the following hypotheses: (1) older adults with SMC who are $A P O E \& 4$ carriers show $\mathrm{AD}$-like pathology on neuroimaging and CSF biomarkers, including increased amyloid deposition, decreased CSF amyloid beta (A $\beta) 1-42$, increased
CSF total tau (t-tau) and tau phosphorylated at threonine 181 (p-tau), glucose hypometabolism, and MTL neurodegeneration relative to $A P O E \varepsilon 4$ noncarriers; and (2) SMC $A P O E \varepsilon 4$ carriers with cerebral amyloid positivity would show the most abnormalities on CSF biomarkers of amyloid and tau, as these SMC participants carry additional genetic risk and are most likely to show AD-related pathological changes. The analyses associated with the latter hypothesis will allow us to determine whether pathological CSF A $\beta 1-42$ changes are occurring in SMC who are $A P O E$ \&4 positive but below the threshold for amyloid PET positivity, as has been suggested by studies in autosomal dominant AD [32]. Furthermore, these analyses will evaluate whether APOE \&4 positive SMC show the most abnormal changes in tau which would suggest that these individuals are at a highest risk for future cognitive decline. In these analyses, $\mathrm{CN}$ and EMCI participants were included as boundary groups to better characterize the SMC group.

\section{Methods}

\subsection{Alzheimer's Disease Neuroimaging Initiative}

Data used in the preparation of this article were obtained from the Alzheimer's Disease Neuroimaging Initiative (ADNI) database (adni.loni.usc.edu). For more information see Supplementary Material, http://www.adni-info.org, http://adni.loni.usc.edu, and in previous reports [33-38]. Informed consent was obtained according to the Declaration of Helsinki.

\subsection{Participants}

Participants were included if they were diagnosed as CN, SMC, or EMCI. Diagnosis was made using the standard criteria described in the ADNI-2 procedures manual (http:// www.adni-info.org). Briefly, CN participants had no subjective or informant-based complaint of memory decline and normal cognitive performance (adjusted for education level) on the Wechsler Logical Memory Delayed Recall (LMdelayed) and the Mini-Mental State Examination (MMSE); EMCI participants had a memory concern reported by the subject, informant, and/or clinician, abnormal memory function approximately 1 standard deviation below normative performance adjusted for education level on the LM-delayed, a MMSE total score greater than 24, and preserved daily functioning such that a diagnosis of $\mathrm{AD}$ could not be made; SMC participants had subjective memory concerns as assessed using the Cognitive Change Index (CCI; total score from first 12 items $>16$ ), which is based on selected items from a larger compilation of measures analyzed in an independent sample [4], no informant-based complaint of memory impairment or decline, and normal cognitive performance on the LM-delayed recall and MMSE.

All diagnostic groups were further divided based on $A P O E \varepsilon 4$ carrier status (one or more $\varepsilon 4$ alleles $=A P O E$ 
$\varepsilon 4$ positive $[\varepsilon 4+]$; no $\varepsilon 4$ alleles $=A P O E \varepsilon 4$ negative $[\varepsilon 4-]$ ). $A P O E \& 2$ carriers were included in their respective groups ( $\varepsilon 4-$ or $\varepsilon 4+$ ), as the distribution of $A P O E \varepsilon 2$ carriers did not differ across CN, SMC, and EMCI groups. The initial analysis included 594 participants $(132 \mathrm{CN} \varepsilon 4-, 53 \mathrm{CN}$ $\varepsilon 4+, 71$ SMC $\varepsilon 4-, 33$ SMC $\varepsilon 4+, 174$ EMCI $\varepsilon 4-$, and 131 EMCI $\varepsilon 4+)$. The targeted analysis in SMC of the potential interaction between $A P O E \varepsilon 4$ carrier status and amyloid positivity (on $\left[{ }^{18} \mathrm{~F}\right]$ Florbetapir PET) on CSF biomarkers included 90 SMC participants, including 50 APOE $84-$ who were amyloid negative (APOE $\varepsilon 4-$ / $\mathrm{A} \beta-$ ), 12 APOE $\varepsilon 4-$ who were amyloid positive (APOE $\varepsilon 4-/ A \beta+), 12 A P O E \varepsilon 4+$ who were amyloid negative (APOE $\varepsilon 4+/ A \beta-)$, and 16 APOE $\varepsilon 4+$ who were amyloid positive (APOE $\varepsilon 4+/ \mathrm{A} \beta+)$.

\subsection{Clinical and cognitive assessments}

Baseline clinical and cognitive performance data was downloaded from the ADNI data repository (http://adni. loni.usc.edu). Participants received a comprehensive battery of clinical and cognitive tests as described in the ADNI-2 manual (www.adni-info.org). In addition to the CCI, subjective or participant-based cognitive complaints were assessed using the Measure of Everyday Cognition (ECog). Cognitive complaints by the study partner regarding the participant's functioning were also assessed using the ECog (Informant version). We compared the ECog estimate of both participant and informant cognitive complaints between groups to confirm the complaint status of the SMC group, assess the level of complaints within the SMC group relative to $\mathrm{CN}$ and EMCI participants, and to evaluate differences in informant-based complaints across these preclinical and prodromal stages of disease.

\section{4. $\left[{ }^{18}\right.$ F]Florbetapir PET scans}

Preprocessed $\left[{ }^{18}\right.$ F]Florbetapir PET scans (coregistered, averaged, standardized image and voxel size, uniform resolution) were downloaded from Laboratory of Neuro Imaging (http://adni.loni.usc.edu). Images were pre-processed by the ADNI PET core and locally as previously described [31,34]. Scans were intensity-normalized using a whole cerebellum reference region to create standardized uptake value ratio (SUVR) images. The effect of diagnosis and $A P O E \& 4$ carrier status on $\left[{ }^{18} \mathrm{~F}\right]$ Florbetapir SUVR was assessed on a voxel-wise basis using a two-way analysis of covariance (ANCOVA), masked for the whole brain, and covaried for age and gender. Significant results were displayed at a voxel-wise threshold of $P<.001$ (uncorrected for multiple comparisons (unc.)) and minimum cluster size (k) of 300 voxels. A more stringent voxel-wise statistical threshold of $P<.05$ (family-wise error), $\mathrm{k}=10$ voxels was also evaluated in SMC (Supplementary Fig. 1). Statistical Parametric Mapping 8 (SPM8; Wellcome Department of Cognitive Neuroscience, London, UK; http://www.fil.ion. ucl.ac.uk/spm/software/spm8/) was used for all processing and voxel-wise analysis. Mean SUVR values were extracted using MarsBaR [39] from two regions of interest (ROIs), including a global cortical region generated from an independent comparison of ADNI-1 $\left[{ }^{11} \mathrm{C}\right]$ Pittsburgh Compound B SUVR scans (regions where $\mathrm{AD}>\mathrm{CN}$ ) and an anatomically-defined bilateral precuneus ROI [39]. A total of 17 participants $(5 \mathrm{CN} \varepsilon 4-, 2 \mathrm{CN} \varepsilon 4+, 5 \mathrm{SMC}$ $\varepsilon 4+, 4$ EMCI $\varepsilon 4-, 1$ EMCI $\varepsilon 4+$ ) were excluded from $\left[{ }^{18} \mathrm{~F}\right]$ Florbetapir analyses for missing data.

\section{5. $\left[{ }^{18} F\right] F D G$ PET scans}

Preprocessed $\left[{ }^{18} \mathrm{~F}\right] \mathrm{FDG}$ PET scans (Coregistered, Averaged, Standardized Image and Voxel Size, Uniform Resolution) were downloaded from LONI (http://adni.loni. usc.edu) and processed as has been previously described [31,34]. Scans were then intensity-normalized using a pons ROI to create $\left[{ }^{18} \mathrm{~F}\right]$ FDG SUVR images. Mean SUVR values were extracted from two ROIs, including a global cortical ROI generated from an independent comparison of baseline ADNI-1 $\left[{ }^{18}\right.$ F]FDG SUVR scans (regions where CN $>$ AD) and an anatomically-defined bilateral parietal lobe ROI [39]. A total of 15 participants (4 $\mathrm{CN} \varepsilon 4-, 1 \mathrm{CN} \varepsilon 4+, 2 \mathrm{SMC}$ घ4-, 5 SMC $\varepsilon 4+, 3$ EMCI $\varepsilon 4-)$ were excluded from $\left[{ }^{18}\right.$ F]FDG PET analyses for missing data.

\subsection{Structural MRI}

All available baseline structural MRI scans were downloaded from LONI for included participants. Scans were corrected before download as previously described (www.adni.loni.usc.edu; [33,40]). Scans were processed using Freesurfer version 5.1, as described in previous reports [31,41,42], to extract hippocampal volumes, entorhinal cortex thickness measures, and total intracranial volume (ICV). If two MRI scans were available, values were averaged for each participant from both processed scans. A total of 4 participants (1 CN $84-, 3$ SMC $84-)$ were excluded from this analysis for missing data.

\subsection{CSF biomarkers}

Lumbar punctures and CSF sample preparation were completed as described in the ADNI manual (http://adni. loni.usc.edu/research/protocols/biospecimens-protocols/). CSF A $\beta 1-42, t-t a u$, and p-tau were measured using the multiplex xMAP Luminex platform with the Innogenetics/ Fujirebio AlzBio3 research use only immunoassay kit based reagents (Fujirebio, Ghent, Belgium) as described previously [43]. Analysis and quality control procedures appear online (http://adni.loni.usc.edu/). CSF aliquots in this analysis were collected at the baseline ADNI-Grand Opportunity (GO)/2 visit and were scaled to the ADNI-1 baseline data set using linear regression to use the abnormal cut-off values that were previously established [44]. 86 participants (20 CN $\varepsilon 4-, 11 \mathrm{CN} \varepsilon 4+, 9$ SMC $\varepsilon 4-$, 
2 SMC $\varepsilon 4+, 21$ EMCI $\varepsilon 4-, 23$ EMCI $\varepsilon 4+$ ) were excluded from CSF analyses for missing data.

\subsection{Statistical analyses}

For the initial analyses, we evaluated the effect of diagnosis and $A P O E \& 4$ status on target measures using two-way ANCOVA for continuous variables and a chi-square test for categorical variables implemented in SPSS 21.0 (SPSS Statistics 21, IBM Corporation, Somers, NY). Post-hoc analyses used a Bonferroni correction for multiple comparisons. Specifically, the effects of diagnosis, $A P O E \quad \& 4$ carrier status, and their interaction on demographics, clinical and psychometric test performance, patient and informant cognitive complaints, regional amyloid deposition ( $\left[{ }^{18}\right.$ F $]$ Florbetapir SUVR), regional glucose metabolism ( $\left[{ }^{18} \mathrm{~F}\right] \mathrm{FDG}$ SUVR), brain atrophy (hippocampal volume and entorhinal cortex thickness), and CSF levels of A $\beta 1-42$, t-tau, and p-tau were assessed. We tested for the normality of the evaluated measures and found that the measures of CSF amyloid and tau, $\left[{ }^{18} \mathrm{~F}\right]$ Florbetapir SUVR, and entorhinal cortex thickness were not normally distributed. We log-transformed these variables and repeated the previous analyses. However, this log-transformation did not alter the findings observed with the raw variables. Therefore, we present the findings obtained by the analysis of the raw values in the present report. A further targeted analysis in SMC participants of an interaction between $A P O E \varepsilon 4$ carrier status and amyloid positivity established using $\left[{ }^{18} \mathrm{~F}\right]$ Florbetapir PET scans (cut-off of 1.52 in the global cortical ROI was selected due to maximal classification of $\mathrm{AD}$ vs. $\mathrm{CN}$ patients in the full ADNI-GO/2 sample and amyloid positive vs. negative defined using a previously reported cut-off [45]) was completed. Specifically, a two-way ANCOVA was used to evaluate the effect of $A P O E \varepsilon 4$ status, amyloid positivity, and their interaction on CSF levels of A $\beta 1-42$, t-tau, and p-tau. All PET and CSF biomarker analyses were covaried for age and gender. Analyses of cognition were covaried for age, gender, and years of education. Finally, analyses of brain atrophy were covaried for age, gender, and total ICV. Given the known association of depressive symptoms with subjective cognitive decline, we repeated the analyses including the total score of the Geratric Depression Scale (GDS) as a covariate. Inclusion of the GDS total score as a covariate did not change any of the observed results and thus, is not included in the final results presented in the present report.

\section{Results}

\subsection{Demographics, cognition, and cognitive complaints}

Effects of diagnosis and APOE \&4 carrier status on demographics, clinical and neuropsychological test performance, and patient- and informant-based complaints are shown in Table 1. Age and education level were different among diagnostic groups $(P<.05)$, whereas only age was associated with $A P O E \& 4$ status $(P=.003)$. Gender was significantly associated with the interaction of diagnosis and $A P O E$ e4 carrier status only. Unsurprisingly, clinical and neuropsychological test performance was significantly different among diagnostic groups $(P<.001)$, with EMCI showing impairment relative to $\mathrm{CN}$ and/or SMC on all cognitive measures $(P<.05)$. EMCI had greater self- and informant-based complaints than $\mathrm{CN}$ and/or SMC on the ECog $(P<.05)$. SMC participants had greater self-based complaints than $\mathrm{CN}$ in all domains and greater informantbased complaints in the memory domain only (specifically SMC $\varepsilon 4->\mathrm{CN} ; P<.05)$. APOE $\varepsilon 4$ carrier status was also significantly associated with selected measures of memory and executive performance (all $P<.05$ ), with $\varepsilon 4+$ participants showing poorer performance than $\varepsilon 4-$. See Table 1 for complete results.

\subsection{Voxel-wise analysis of amyloid PET}

A main effect of $A P O E \& 4$ carrier status was observed with $A P O E$ E4+ participants showing greater amyloid deposition than APOE $\varepsilon 4-$ participants across diagnostic groups in nearly the entire cortex (Fig. 1A; voxel-wise threshold $P<.001$ [unc.]; $\mathrm{k}=300$ voxels). A main effect of diagnosis was also observed (EMCI $>$ SMC $>\mathrm{CN}$ ), with significant clusters seen in primarily the frontal, temporal, and medial parietal cortices (Fig. 1B; voxel-wise threshold $P<.001$ [unc.]; $\mathrm{k}=300$ voxels). A significant effect of $A P O E \& 4$ carrier status was also observed within each diagnostic group. Similar to our previous report in a smaller sample, $\mathrm{CN}$ and EMCI $\varepsilon 4+$ participants showed greater amyloid deposition in widespread cortical regions than $\mathrm{CN}$ and EMCI $\varepsilon 4-$ participants, respectively (Fig. 1C and E). Similar patterns were observed in SMC participants, with $\varepsilon 4+$ showing greater amyloid deposition in frontal, parietal, cingulate, temporal, and occipital lobar regions than $\varepsilon 4-$ (Fig. 1D). When a more stringent statistical threshold was applied, SMC $\varepsilon 4+$ showed greater amyloid deposition in the bilateral cingulate and frontal, parietal, and temporal lobes than SMC $\varepsilon 4-$ (Supplementary Fig. 1). No regions showed higher amyloid deposition in $\varepsilon 4-$ than $\varepsilon 4+$ in either the main effect analysis or within each diagnostic group.

\subsection{Regional analysis of amyloid PET}

Regional estimates of amyloid showed a similar pattern to that observed in the voxel-wise analyses (Fig. 2). Global cortical (Fig. 2A) and bilateral precuneus (Fig. 2B) amyloid deposition were significantly associated with both diagnosis (global cortical: $P=.004$; precuneus: $P=.006$ ) and $A P O E$ $\varepsilon 4$ carrier status (Fig. 2A; both $P<.001$ ). In both regions, $\varepsilon 4+$ showed greater amyloid deposition than $\varepsilon 4-$ within each diagnostic group (for global cortex: $\mathrm{CN} \varepsilon 4+>\mathrm{CN}$ $\varepsilon 4-, P=.052$; all other comparisons $P<.05)$. Furthermore, 
Table 1

Demographic, cognitive performance, and patient and informant complaints

\begin{tabular}{|c|c|c|c|c|c|c|c|c|c|c|}
\hline & $\begin{array}{l}\mathrm{CN} \varepsilon 4- \\
(\mathrm{n}=132)\end{array}$ & $\begin{array}{l}\mathrm{CN} \varepsilon 4+ \\
(\mathrm{n}=53)\end{array}$ & $\begin{array}{l}\text { SMC } \varepsilon 4- \\
(\mathrm{n}=71)\end{array}$ & $\begin{array}{l}\text { SMC } \varepsilon 4+ \\
(\mathrm{n}=33)\end{array}$ & $\begin{array}{l}\text { EMCI } \varepsilon 4- \\
(\mathrm{n}=174)\end{array}$ & $\begin{array}{l}\text { EMCI } 84+ \\
(\mathrm{n}=131)\end{array}$ & $\begin{array}{l}\text { DX, } \\
\text { p-val }\end{array}$ & $\begin{array}{l}A P O E \\
\text { p-val }\end{array}$ & $\begin{array}{l}\text { DX by } \\
A P O E \\
\text { p-val }\end{array}$ & $\begin{array}{l}\text { Significant pairs } \\
\text { (Bonferroni } P<.05 \text { ) }\end{array}$ \\
\hline Education (yrs) & $5.7(2.5)$ & $16.2(2.6)$ & $16.6(2.7)$ & $17.2(2.0)$ & $16.1(2.6)$ & $15.8(2.7)$ & .009 & .770 & .298 & None \\
\hline Gender $(\mathrm{M}, \mathrm{F})$ & 68,64 & 21,32 & 31,40 & 12,21 & 88,86 & 81,50 & .078 & .491 & .021 & $\mathrm{n} / \mathrm{a}$ \\
\hline CDR-SB & $0.03(0.12)$ & $0.04(0.17)$ & $0.09(0.19)$ & $0.06(0.17)$ & $1.22(0.68)$ & $1.39(0.85)$ & $<.001$ & .359 & .174 & $\begin{array}{l}\mathrm{EMCI}+/->\mathrm{SMC}+/-, \\
\quad \mathrm{CN}+/-\end{array}$ \\
\hline $\begin{array}{l}\text { MMSE total } \\
\text { score* }\end{array}$ & $29.1(1.3)$ & $28.9(1.2)$ & $28.9(1.2)$ & $29.0(1.2)$ & $28.5(1.4)$ & $28.1(1.7)$ & $<.001$ & .171 & .304 & $\begin{array}{l}\mathrm{CN}+/-, \mathrm{SMC}+/- \\
\quad>\mathrm{EMCI}+; \mathrm{CN}- \\
\quad>\mathrm{EMCI}-\end{array}$ \\
\hline $\begin{array}{l}\text { MoCA total } \\
\text { score* }^{\dagger}\end{array}$ & $25.8(2.3)$ & $25.6(2.4)$ & $25.5(2.8)$ & $25.3(2.5)$ & $24.1(2.9)$ & $23.5(3.2)$ & $<.001$ & .188 & .609 & $\begin{array}{l}\mathrm{CN}+/-, \mathrm{SMC}- \\
\quad>\mathrm{EMCI}+/-; \mathrm{SMC}+ \\
\quad>\mathrm{EMCI}+\end{array}$ \\
\hline $\begin{array}{l}\text { LM-delayed } \\
\text { recall* }\end{array}$ & $13.6(2.9)$ & $13.0(3.2)$ & $13.1(3.0)$ & $12.7(3.8)$ & $8.9(1.9)$ & $9.1(1.6)$ & $<.001$ & .208 & .183 & $\begin{array}{l}\mathrm{CN}+/-, \mathrm{SMC}+/- \\
>\mathrm{EMCI}+/-\end{array}$ \\
\hline RAVLT total* & $46.6(10.8)$ & $44.4(10.0)$ & $46.1(9.5)$ & $43.3(10.4)$ & $40.8(10.9)$ & $38.2(10.5)$ & $<.001$ & .005 & .954 & $\begin{array}{l}\mathrm{CN}-, \mathrm{SMC}- \\
\quad>\mathrm{EMCI}+/-; \mathrm{CN}+ \\
\quad>\mathrm{EMCI}+\end{array}$ \\
\hline RAVLT delayed* & $7.8(4.2)$ & $7.2(3.7)$ & $7.8(4.0)$ & $6.5(3.9)$ & $6.2(4.2)$ & $5.4(3.9)$ & $<.001$ & .017 & .784 & $\begin{array}{l}\mathrm{CN}-, \mathrm{SMC}- \\
\quad>\mathrm{EMCI}+/-; \mathrm{CN}+ \\
\quad>\mathrm{EMCI}+\end{array}$ \\
\hline Animal fluency* & $21.3(5.4)$ & $22.2(5.1)$ & $19.9(5.2)$ & 19.7 (5.6) & $19.1(5.2)$ & $18.1(5.0)$ & $<.001$ & .843 & .135 & $\mathrm{CN}+/->\mathrm{EMCI}+/-$ \\
\hline $\begin{array}{l}\text { Trail making } \\
\text { part } \mathrm{B}^{\ddagger}, *\end{array}$ & $76.7(38.3)$ & $83.9(50.0)$ & $88.8(49.7)$ & $89.8(35.6)$ & $91.6(40.7)$ & $111.0(59.4)$ & $<.001$ & .030 & .134 & $\begin{array}{l}\mathrm{EMCI}+>\mathrm{SMC}- \\
\mathrm{CN}+/-\end{array}$ \\
\hline $\begin{array}{l}\text { Memory } \\
\text { composite* }\end{array}$ & $0.94(0.52)$ & $0.87(0.56)$ & $0.91(0.46)$ & $0.81(0.48)$ & $0.59(0.50)$ & $0.45(0.47)$ & $<.001$ & .013 & .731 & $\begin{array}{l}\mathrm{CN}+/-, \mathrm{SMC}- \\
\quad>\mathrm{EMCI}+/-; \mathrm{SMC}+ \\
\quad>\mathrm{EMCI}+\end{array}$ \\
\hline $\begin{array}{l}\text { ECog PT: } \\
\quad \text { executive }^{\S},\end{array}$ & $1.26(0.32)$ & $1.24(0.34)$ & $1.42(0.36)$ & $1.55(0.40)$ & $1.62(0.58)$ & $1.69(0.56)$ & $<.001$ & .236 & .440 & $\begin{array}{c}\mathrm{EMCI}+/->\mathrm{CN}+/- \\
\mathrm{EMCI}+>\mathrm{SMC}- \\
\mathrm{SMC}+>\mathrm{CN}-\end{array}$ \\
\hline $\begin{array}{l}\text { ECog PT: } \\
\text { global }^{\S}\end{array}$ & $1.31(0.29)$ & $1.30(0.32)$ & $1.54(0.33)$ & $1.65(0.38)$ & $1.76(0.54)$ & $1.82(0.50)$ & $<.001$ & .257 & .566 & $\begin{array}{l}\mathrm{EMCI}+/-, \mathrm{SMC}+/- \\
\quad>\mathrm{CN}+/-; \mathrm{EMCI}+/- \\
\quad>\mathrm{SMC}-\end{array}$ \\
\hline $\begin{array}{l}\text { ECog Inf: } \\
\text { memory }\end{array}$ & $1.24(0.38)$ & $1.29(0.31)$ & $1.62(0.55)$ & $1.50(0.44)$ & $1.96(0.70)$ & $2.10(0.77)$ & $<.001$ & .764 & .202 & $\begin{array}{l}\mathrm{EMCI}+/->\mathrm{SMC}+/- \\
\mathrm{CN}+/-; \mathrm{SMC}-> \\
\mathrm{CN}+/-\end{array}$ \\
\hline $\begin{array}{l}\text { ECog Inf: } \\
\quad \text { executive }\end{array}$ & $1.16(0.36)$ & $1.17(0.27)$ & $1.31(0.45)$ & $1.24(0.32)$ & $1.54(0.55)$ & $1.66(0.70)$ & $<.001$ & .656 & .243 & $\begin{array}{l}\mathrm{EMCI}+/->\mathrm{SMC}+/-, \\
\mathrm{CN}+/-\end{array}$ \\
\hline $\begin{array}{l}\text { ECog Inf: } \\
\text { global }{ }^{-}\end{array}$ & $1.14(0.25)$ & $1.18(0.26)$ & $1.33(0.37)$ & $1.25(0.26)$ & $1.57(0.48)$ & $1.71(0.62)$ & $<.001$ & .475 & .108 & $\begin{array}{l}\mathrm{EMCI}+/->\mathrm{SMC}+/- \\
\mathrm{CN}+/-\end{array}$ \\
\hline
\end{tabular}

Abbreviations: CN, cognitively normal older adults; SMC, significant memory concern; EMCI, early mild cognitive impairment; DX, diagnosis; APOE, $A P O E \& 4$ carrier status; p-val, $P$ value; M, male; F, female; CDR-SB, Clinical Dementia Rating scale Sum of Boxes; GDS, Geriatric Depression Scale; MMSE, Mini-Mental State Examination; MoCA, Montreal Cognitive Assessment; LM, Weschler's Logical Memory test; RAVLT, Rey Auditory Verbal Learning Test; E-Cog, Measurement of Everyday Cognition; PT, patient-based; Inf, Informant-based; NS, not significant.

*Adjusted means and analysis of variance (ANOVA) $P$-values include age, gender, and years of education as covariates.

${ }^{\dagger}$ Missing data of seven participants (two $\mathrm{CN} \varepsilon 4-$, one SMC $\varepsilon 4-$, one SMC $\varepsilon 4+$, one EMCI $\varepsilon 4-$, one EMCI $\varepsilon 4+$ ).

${ }^{\ddagger}$ Missing data of five participants (one $\mathrm{CN} \varepsilon 4+$, three EMCI $\varepsilon 4-$, one EMCI $\varepsilon 4+$ ).

${ }^{\S}$ Missing data of 12 participants ( $1 \mathrm{CN} \varepsilon 4-, 2 \mathrm{CN} \varepsilon 4+, 1 \mathrm{SMC} \varepsilon 4-, 1 \mathrm{SMC} \varepsilon 4+, 3 \mathrm{EMCI} \varepsilon 4-, 1 \mathrm{EMCI} \varepsilon 4+$ ).

"Missing data of 28 participants (5 CN $\varepsilon 4-, 1 \mathrm{CN} \varepsilon 4+, 2 \mathrm{SMC} \varepsilon 4-, 3 \mathrm{SMC} \varepsilon 4+, 9$ EMCI $\varepsilon 4-, 8 \mathrm{EMCI} \varepsilon 4+$ ).

ॠAdjusted means and ANOVA $P$-values include age and gender as covariates. 
A

\section{Main Effect} of $A P O E$

( $\varepsilon 4+>\varepsilon 4-)$

B

Main Effect of Diagnosis $(\mathrm{EMCI}>\mathrm{SMC}>\mathrm{CN})$

C
$\mathrm{CN} \varepsilon 4+>$

$\mathrm{CN} \varepsilon 4-$

D

SMC \&4+>

SMC \&4-

E

EMCI $\varepsilon 4+>$

EMCI \&4-
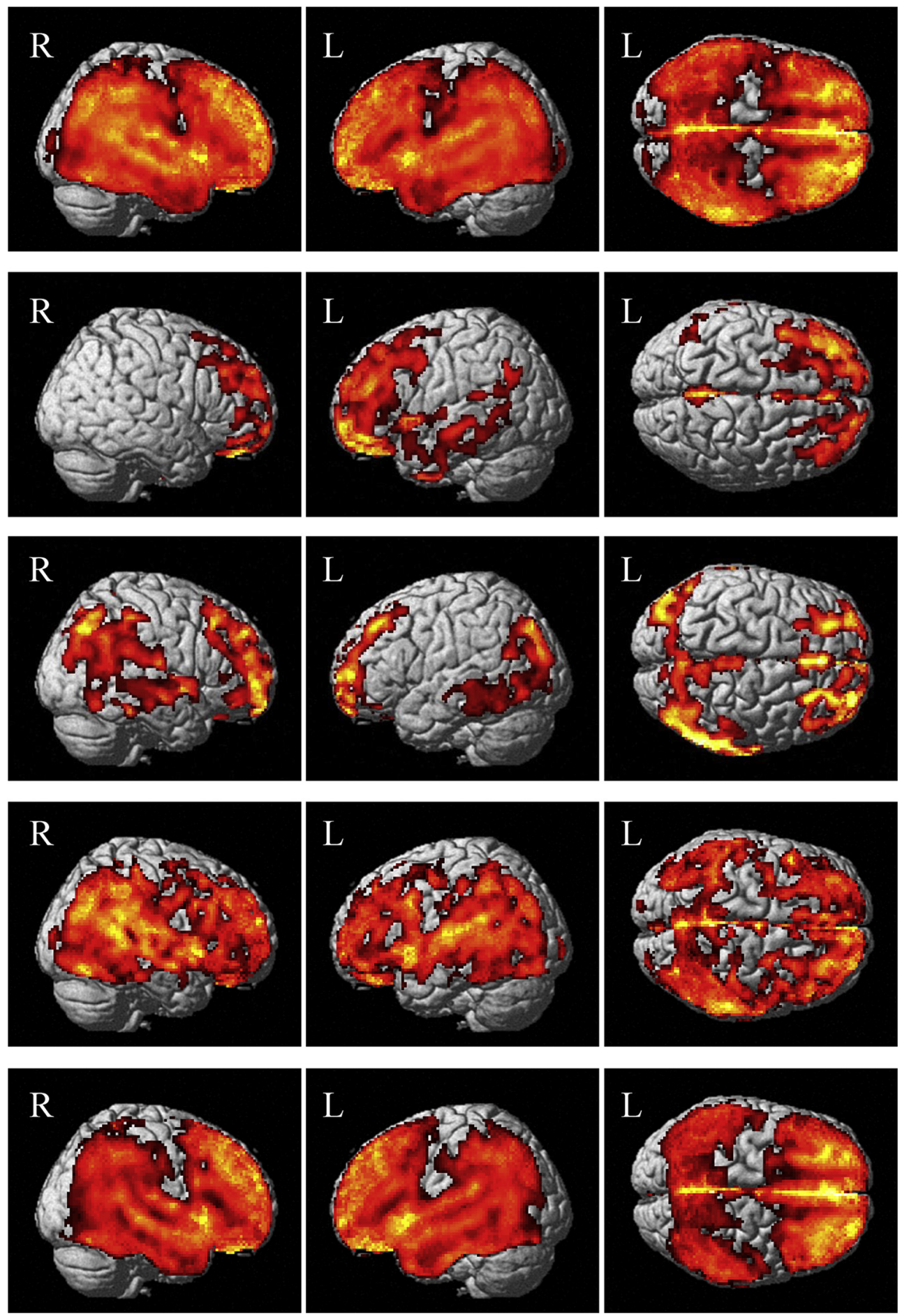

Fig. 1. Impact of diagnosis and apolipoprotein $\mathrm{E}(A P O E) \varepsilon 4$ carrier status on cerebral amyloid deposition (A) voxel-wise analysis of $\left[{ }^{18} \mathrm{~F}\right] \mathrm{Florbetapir}$ positron emission tomography (PET) scans showed a main effect of $A P O E \varepsilon 4$ carrier status such that $A P O E \varepsilon 4+$ participants had greater amyloid deposition than $A P O E$ $\varepsilon 4-$ participants in nearly the entire cortex. (B) A main effect of diagnostic group (EMCI $>$ SMC $>\mathrm{CN}$ ) was also observed in more restricted regions of the frontal, temporal, and medial parietal cortices. Significant effects of $A P O E \varepsilon 4$ carrier status within diagnostic groups were also observed, including in (C) CN participants (127 CN $\varepsilon 4-, 51 \mathrm{CN} \varepsilon 4+)$, (D) SMC participants (71 SMC $\varepsilon 4-, 28 \mathrm{SMC} \varepsilon 4+$ ), and (E) EMCI participants (170 EMCI $\varepsilon 4-, 130 \mathrm{EMCI} \varepsilon 4+)$ in widespread cortical regions, including in the frontal, parietal, temporal, and occipital lobes. No regions showed higher amyloid deposition in $A P O E \varepsilon 4$ noncarriers than $A P O E \& 4$ carriers. Figure is displayed at a voxel-wise threshold of $P<.001$ (uncorrected for multiple comparisons); minimum voxel size $(\mathrm{k})=300$ voxels, which corresponds to a cluster-wise threshold of $P<.05$ (family-wise error [FWE] correction for multiple comparison). Abbreviations: EMCI, early mild cognitive impairment; SMC, significant memory concern; CN, cognitively normal. 
A

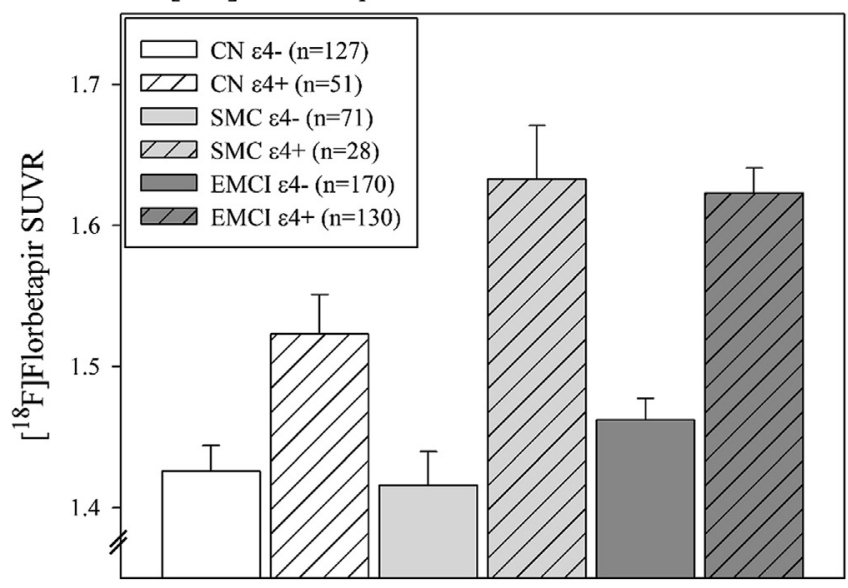

B

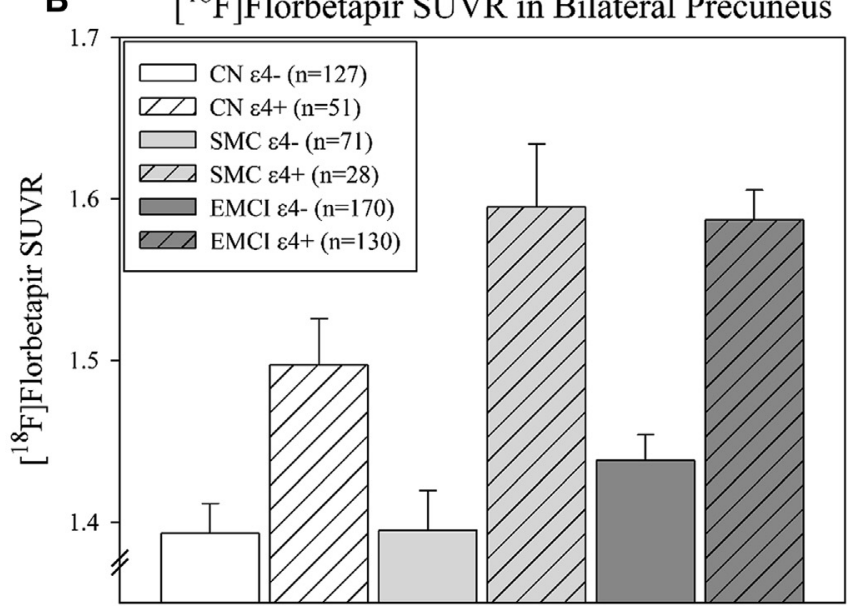

Fig. 2. Impact of diagnosis and apolipoprotein $\mathrm{E}(A P O E) \varepsilon 4$ carrier status on regional amyloid deposition. Regional analysis of amyloid deposition on $\left[{ }^{18} \mathrm{~F}\right]$ Florbetapir positron emission tomography (PET) showed that $A P O E \varepsilon 4+$ participants had a greater amyloid deposition than $A P O E \varepsilon 4-$ participants in (A) a global cortical region of interest, and within the (B) bilateral precuneus, across all diagnostic groups (APOE $\varepsilon 4$ carrier status: both $P<.001$ ). Diagnostic group was also significantly associated with amyloid deposition in both target regions (diagnosis: both $P<.01$ ). In Bonferroni-corrected post-hoc pair comparisons, SMC and EMCI $\varepsilon 4+$ participants showed higher amyloid than CN $\varepsilon 4-$, SMC $\varepsilon 4-$, and EMCI $\varepsilon 4-$ participants in both ROIs (all $P<.05$ ), CN $\varepsilon 4+$ participants had higher amyloid than $\mathrm{CN} \varepsilon 4-$ in the global cortex $(\mathrm{A} ; P=.052)$ and bilateral precuneus $(\mathrm{B} ; P<.05)$, and EMCI $\varepsilon 4+$ participants had greater amyloid deposition in the global cortical ROI than $\mathrm{CN} \varepsilon 4+$ participants (A; $P<.05$ ). No significant interaction effect of diagnostic group and $A P O E \varepsilon 4$ carrier status was observed, although a trend for an interaction effect on global cortical amyloid deposition was observed (A; $P=.084)$. Abbreviations: EMCI, early mild cognitive impairment; SMC, significant memory concern; $\mathrm{CN}$, cognitively normal.

SMC $\varepsilon 4+$ and EMCI $\varepsilon 4+$ participants showed greater amyloid deposition in both ROIs than $\mathrm{CN} \varepsilon 4-$, SMC $\varepsilon 4-$, and EMCI $\varepsilon 4-$ participants (all $P<.05$ ). Finally, EMCI $\varepsilon 4+$ had greater amyloid deposition in the global cortical ROI than $\mathrm{CN} \varepsilon 4+(P<.05)$.

\subsection{Glucose metabolism}

Diagnosis was significantly associated with glucose metabolism in both the global cortical $(P=.001)$ and the mean parietal lobe $(P=.048)$ measures. Furthermore, a significant interaction effect between diagnosis and $A P O E$ $\varepsilon 4$ carrier status was observed in both regions (global cortical ROI: $P=.014$; mean parietal ROI: $P=.016$ ). On post-hoc comparison, EMCI $\varepsilon 4+$ had reduced glucose metabolism in the global cortical ROI (Fig. 3A) relative to CN $\varepsilon 4-$, SMC $\varepsilon 4-$, SMC $\varepsilon 4+$, and EMCI $\varepsilon 4-$ (all $P<.05)$. The mean parietal lobe glucose metabolism was only significantly reduced in EMCI $\varepsilon 4+$ relative to EMCI $\varepsilon 4-$ on post-hoc comparison $(P<.05)$.

\subsection{Medial temporal lobe neurodegeneration}

Hippocampal volume (Fig. 3C) and entorhinal cortex thickness (Fig. 3D) were associated with diagnosis (hippocampal volume: $P<.001$; entorhinal cortex thickness: $P=.003$ ). Post-hoc comparisons showed that hippocampal volume was reduced in EMCI $\varepsilon 4+$ and $\varepsilon 4-$ relative to $\mathrm{CN} \varepsilon 4-$ and $\mathrm{SMCI} \varepsilon 4+($ all $P<.05$ ). Hippocampal volume was also significantly reduced in EMCI $\varepsilon 4-$ relative to $\mathrm{CN} \varepsilon 4+(P<.05)$. Entorhinal cortex thickness was reduced in EMCI $\varepsilon 4-$ relative to $\mathrm{CN} \varepsilon 4-$ participants $(P<.05)$.

\subsection{CSF measures of A $\beta 1-42, t$-tau, and p-tau}

Significant independent effects of both diagnostic group $(P=.023)$ and $A P O E \& 4$ carrier status $(P<.001)$ on CSF A $\beta 1-42$ were observed (Fig. 4A). On post-hoc analysis, $\varepsilon 4+$ participants showed lower CSF A $\beta 1-42$ than $\varepsilon 4-$ participants regardless of diagnostic group (all $P<.05$ ). Significant effects of diagnosis and APOE $\varepsilon 4$ carrier status, and their interaction, on CSF t-tau were observed (Fig. 4B; diagnosis: $P<.001$, APOE: $P<.001$, interaction: $P=.002)$, with EMCI $\varepsilon 4+$ showing higher t-tau levels than $\mathrm{CN} \varepsilon 4-, \mathrm{CN} \varepsilon 4+, \mathrm{SMC} \varepsilon 4-$, and EMCI $\varepsilon 4-$ (all $P<.05)$ on post-hoc analysis. Only $A P O E \varepsilon 4$ carrier status was associated with CSF p-tau level (Fig. 4C; $P<.001$ ). On post-hoc analysis, EMCI and SMC $\varepsilon 4+$ participants showed higher p-tau levels than CN, SMC, and EMCI $\varepsilon 4-$ participants (all $P<.05$ ).

\subsection{Interaction of APOE $\varepsilon 4$ carrier status and amyloid PET positivity in SMC participants}

Finally, we sought to investigate the potential interaction effect of cerebral amyloid deposition (measured using $\left[{ }^{18} \mathrm{~F}\right]$ Florbetapir PET) and APOE \&4 carrier status on CSF amyloid and tau measures in SMC (Fig. 5). A significant relationship between cerebral amyloid deposition and CSF A $\beta 1-42$ was observed (Fig. 5A; $P<.001$ ). APOE $\varepsilon 4$ carrier status was also independently associated with CSF A $\beta 1-42(P<.001)$. On post-hoc analysis, decreasing CSF A $\beta 1-42$ level by the interaction of amyloid and/or $A P O E \varepsilon 4$ positivity was seen (Fig. 5A), as SMC APOE $\varepsilon 4-/ \mathrm{A} \beta-$ showed higher CSF A $\beta 1-42$ levels than SMC 

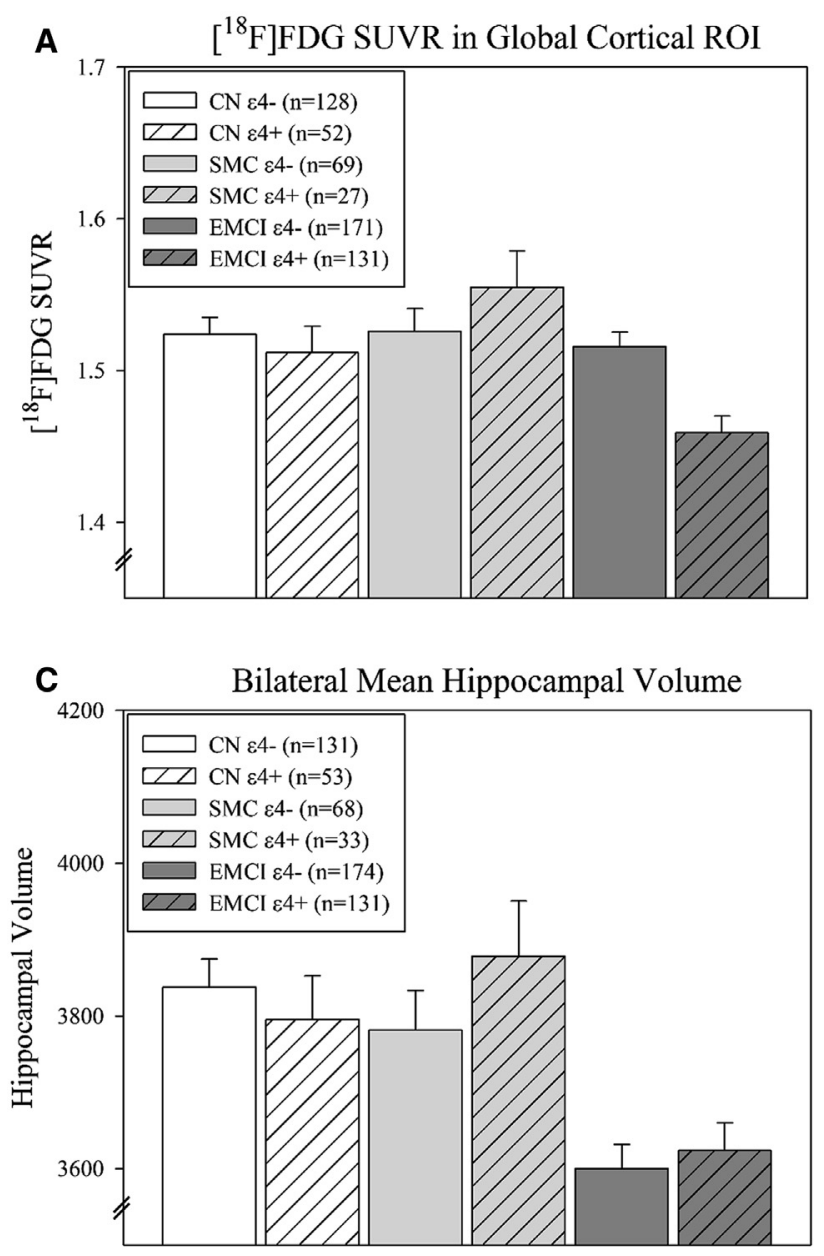

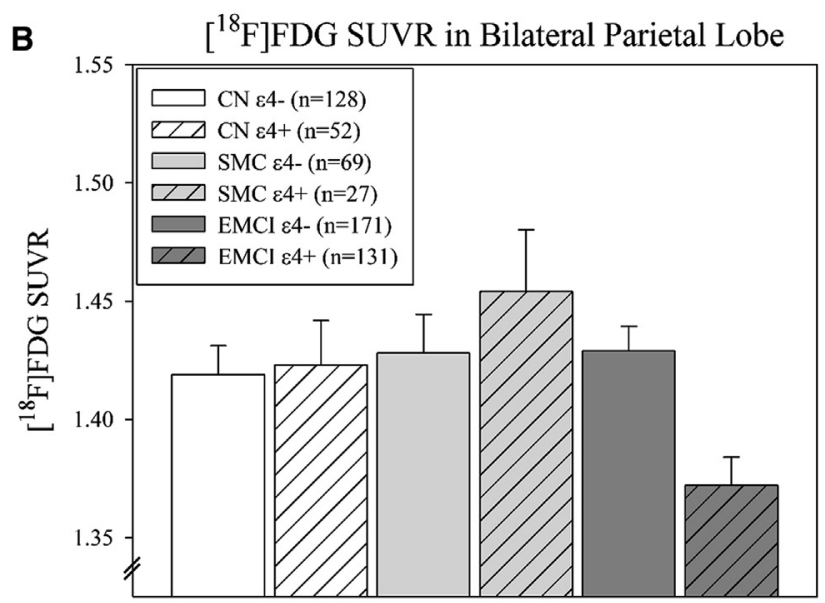

D

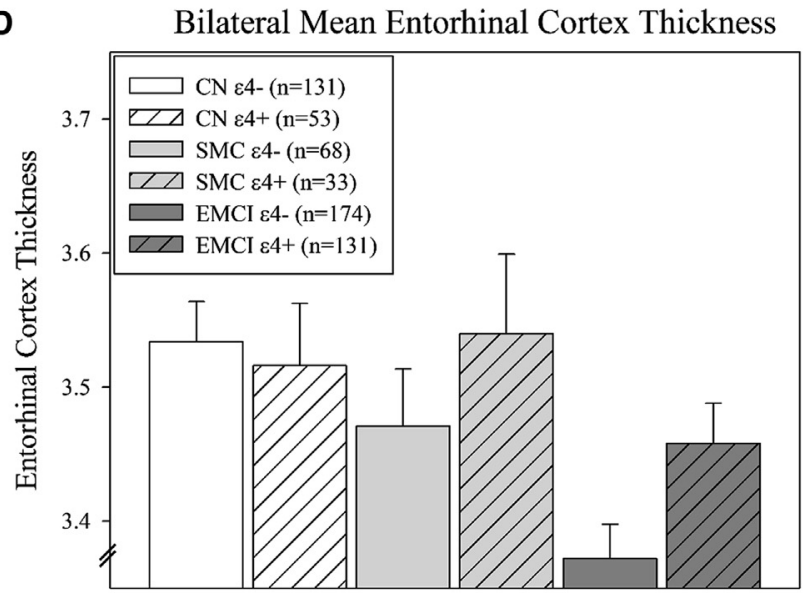

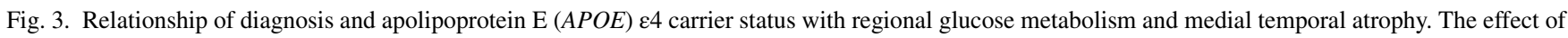
diagnostic group and $A P O E \varepsilon 4$ carrier status on (A) global cortical and (B) parietal lobe glucose metabolism, (C) hippocampal volume, and (D) entorhinal cortex thickness was evaluated. No significant independent effect of $A P O E \varepsilon 4$ carrier status on CN, SMC, or EMCI participants in any measure interest was observed,

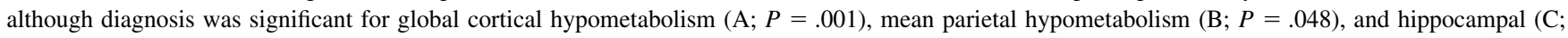
$P<.001)$ and entorhinal cortex $(\mathrm{D} ; P=.003)$ atrophy. A significant interaction effect on hypometabolism, but not atrophy, between diagnosis and $A P O E$ $\varepsilon 4$ carrier status was observed (global cortex: $P=.014$; mean parietal lobe: $P=.016$ ). Post-hoc analyses showed that EMCI $\varepsilon 4+$ participants had reduced glucose metabolism relative to $\mathrm{CN} \varepsilon 4-$, SMC $\varepsilon 4-$, SMC $\varepsilon 4+$, and EMCI $\varepsilon 4-$ in the global cortical region $($ A; all $P<.05)$ and relative to EMCI $\varepsilon 4-$ participants only in the mean parietal lobe $(\mathrm{B} ; P<.05)$. Furthermore, post-hoc comparisons showed that $(\mathrm{C})$ hippocampal volume was significantly reduced in EMCI participants regardless of $A P O E \varepsilon 4$ carrier status relative to $\mathrm{CN} \varepsilon 4-$ and SMCI $\varepsilon 4+$ participants, and in EMCI $\varepsilon 4-$ participants relative to $\mathrm{CN} \varepsilon 4+$ participants (all $P<.05$ ). (D) Entorhinal cortex thickness was reduced in EMCI $\varepsilon 4-$ relative to CN $\varepsilon 4-$ participants $(P<.001)$. Abbreviations: EMCI, early mild cognitive impairment; SMC, significant memory concern; $\mathrm{CN}$, cognitively normal.

$A P O E \varepsilon 4+/ \mathrm{A} \beta+$, and those carrying either an $A P O E \varepsilon 4$ allele $(A P O E \varepsilon 4+/ \mathrm{A} \beta-)$ or are amyloid positive $(A P O E$ $\varepsilon 4-/ \mathrm{A} \beta+)($ all $P<.05)$. In addition, SMC APOE $\varepsilon 4+/$ $\mathrm{A} \beta-$ had higher CSF A $\beta 1-42$ levels than APOE $\varepsilon 4+/$ $\mathrm{A} \beta+(P<.05)$. APOE $\varepsilon 4$ carrier status was significantly associated with CSF t-tau level in SMC participants (Fig. 5B; $P=.009$ ). Only the difference between $A P O E$ $\varepsilon 4+/ \mathrm{A} \beta+$ and $A P O E \varepsilon 4-/ \mathrm{A} \beta-$ was significant on posthoc analysis (APOE $\varepsilon 4+/ \mathrm{A} \beta+>A P O E \quad \varepsilon 4-/ \mathrm{A} \beta-$; $P=.008)$. APOE $\varepsilon 4$ carrier status and amyloid positivity were both independently associated with CSF p-tau level (Fig. 5C; APOE, $P=.014$; amyloid positivity, $P=.010$ ). $A P O E \varepsilon 4+/ \mathrm{A} \beta+$ showed increased p-tau levels relative to $A P O E \varepsilon 4-/ \mathrm{A} \beta-$ SMC participants on post-hoc analysis $(P<.001)$.

\section{Discussion}

Our goal was to investigate the impact of $A P O E \varepsilon 4$ carrier status on measures of cognition and cognitive complaints, cerebral amyloid deposition, glucose metabolism, MTL neurodegeneration, and CSF biomarkers of A $\beta 1-42$, t-tau, and p-tau in older adults with SMC. APOE $\varepsilon 4$ positive SMC participants showed increased amyloid deposition throughout the cortex relative to SMC APOE $\varepsilon 4$ noncarriers. Similar patterns of increased amyloid deposition related to the presence of an APOE \&4 allele were also observed in $\mathrm{CN}$ and EMCI groups, as previously reported [31]. However, glucose metabolism and MTL neurodegeneration were not associated with APOE carrier status in SMC participants. Instead, glucose hypometabolism and MTL atrophy were associated 
A
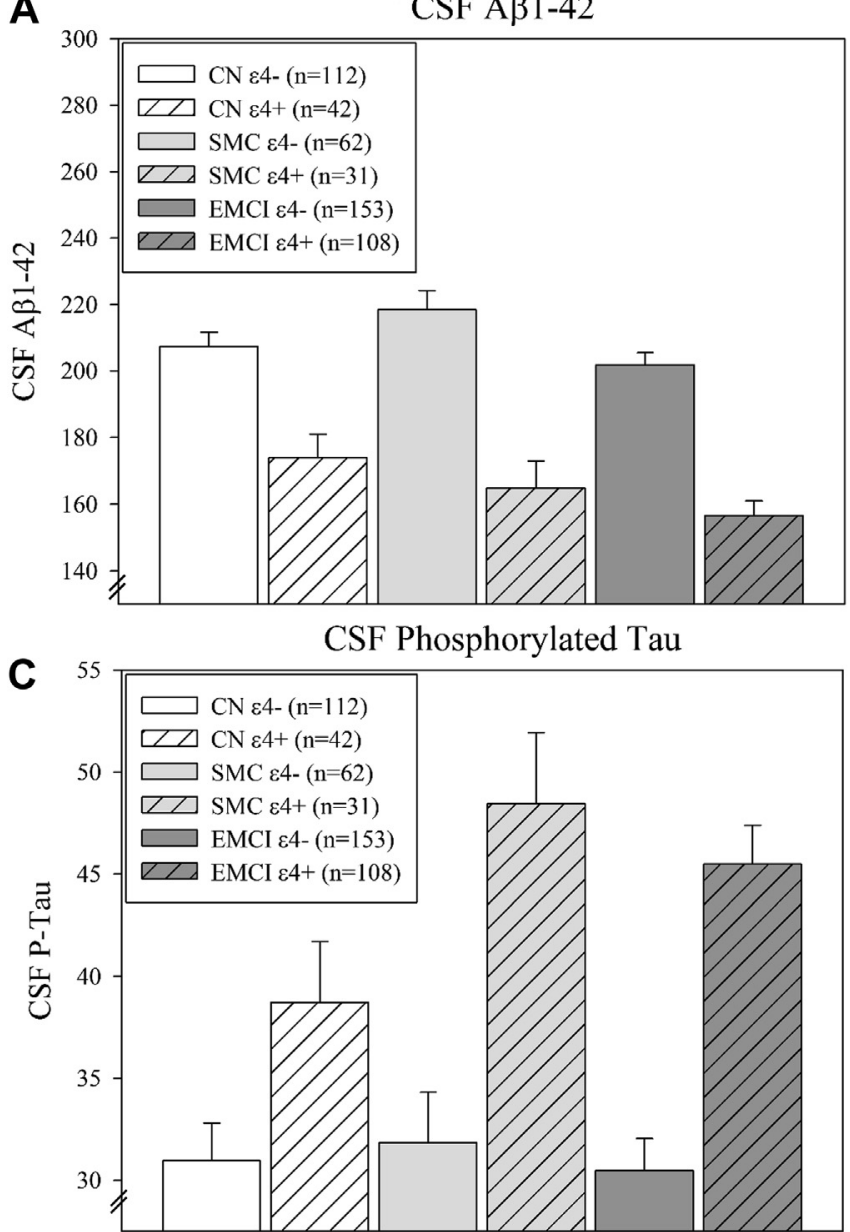

B

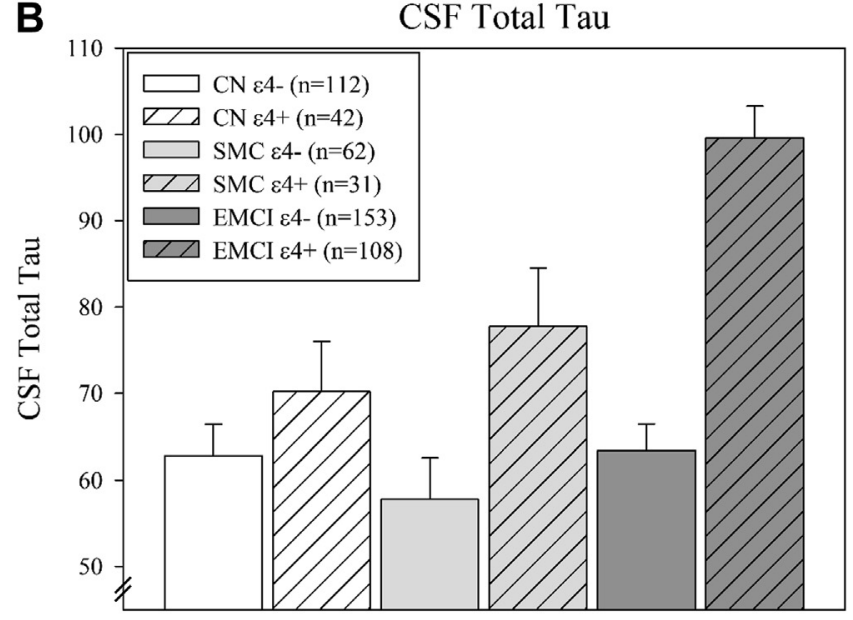

Fig. 4. Relationship of diagnosis and apolipoprotein E (APOE) $\varepsilon 4$ carrier status with cerebrospinal fluid (CSF) protein levels. Diagnostic group and $A P O E \varepsilon 4$ carrier status were significantly associated with CSF levels of (A) A $\beta 1-42$, (B) t-tau, and (C) phosphorylated tau (p-tau). (A) CSF A $\beta 1-42$ levels showed a significant independent effect of both diagnostic group $(P=.023)$ and $A P O E \varepsilon 4$ carrier status $(P<.001)$ but no interaction effect. On post-hoc analysis, $\varepsilon 4+$ participants showed lower CSF A $\beta 1-42$ than $\varepsilon 4-$ participants regardless of diagnostic group (i.e., CN $\varepsilon 4-$, SMC $\varepsilon 4-$, EMCI $\varepsilon 4->$ CN $\varepsilon 4+$, SMC $\varepsilon 4+$, EMCI $\varepsilon 4+$; all $P<.05)$. (B) Significant independent effects of diagnosis and $A P O E \varepsilon 4$ carrier status $(P<.001)$, and an interaction effect between diagnostic group and $A P O E \varepsilon 4$ carrier status $(P=.002)$, on CSF t-tau were also observed. EMCI $\varepsilon 4+$ participants showed higher t-tau levels than $\mathrm{CN} \varepsilon 4-, \mathrm{CN} \varepsilon 4+$, SMC $\varepsilon 4-$, and EMCI $\varepsilon 4-$ participants (all $P<.05$ ) on post-hoc analysis. (C) CSF p-tau level was significantly associated with $A P O E \varepsilon 4$ carrier status only $(P<.001)$. On post-hoc analysis, EMCI and SMC $\varepsilon 4+$ participants showed higher p-tau levels than CN, SMC, and EMCI $\varepsilon 4-$ participants (all $P<.05)$. Abbreviations: A $\beta$, amyloid beta; EMCI, early mild cognitive impairment; SMC, significant memory concern; $\mathrm{CN}$, cognitively normal.

with the presence of mild memory impairment (i.e., EMCI). CSF levels of A $\beta 1-42$ were significantly lower in SMC $A P O E \varepsilon 4+$ relative to SMC APOE $\varepsilon 4-$, similar to $\mathrm{CN}$ and EMCI (as previously reported [31]). CSF t-tau levels were higher in $A P O E$ \& 4 carriers across all diagnostic groups, although the effect within SMC participants (APOE $\varepsilon 4+>A P O E \varepsilon 4-$ ) on post-hoc analysis was not significant. On the other hand, CSF p-tau levels were significantly greater in SMC APOE $\varepsilon 4+$ relative to SMC APOE $\varepsilon 4-$, an effect also observed in EMCI. Finally, we observed the greatest CSF amyloid and tau abnormalities in SMC participants who were both $A P O E \varepsilon 4$ carriers and positive for cerebral amyloid on $\left[{ }^{18}\right.$ F]Florbetapir PET.

The findings in this study support prior findings regarding the importance of $A P O E$ genotype in preclinical stages of late-onset $\mathrm{AD}$. We found an increase in amyloid deposition and abnormal levels of CSF amyloid and tau in older adults with SMC, which was strongly associated with $A P O E \varepsilon 4$ carrier status. However, we did not observe differences in glucose metabolism and MTL atrophy in this population, even in SMC APOE $\varepsilon 4+$, as has been previously reported $[4,13,17,19,21,23,28,46,47]$. Given the previous research in participants with SCD/SMC, the lack of hypometabolism or atrophy is somewhat surprising. However, the absence of these findings is potentially due to different participant recruitment, as SMC participants in the present study were recruited on the basis of subjective memory concerns, whereas many previous reports included participants who also had informant-based complaints. In fact, informant-based complaints have been shown to provide additional predictive ability for the progression to dementia to self-based complaints [5]. Furthermore, the lack of an $A P O E$ effect on MTL atrophy in all groups and metabolism in CN and SMC participants 

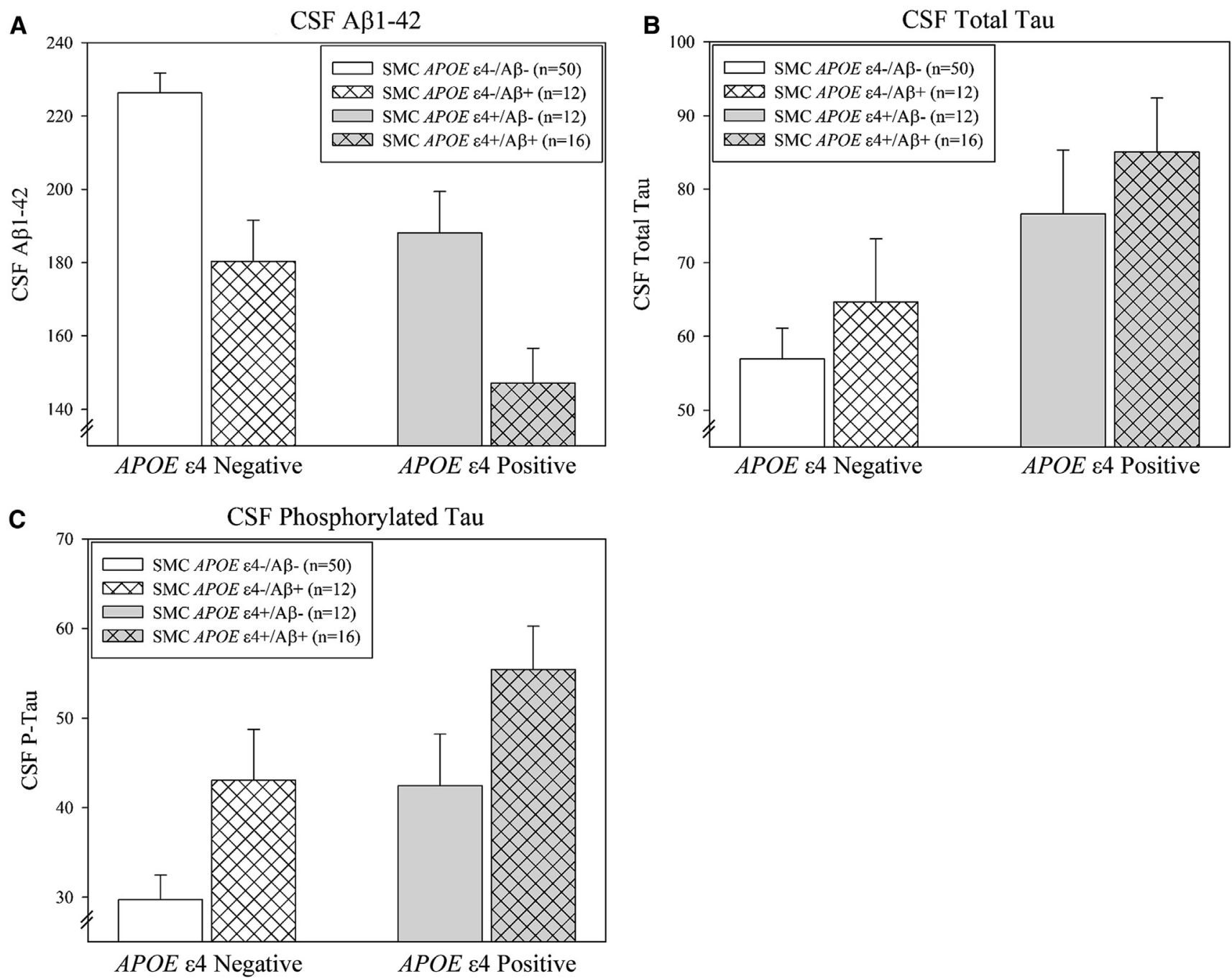

Fig. 5. Effect of apolipoprotein E (APOE) $\varepsilon 4$ carrier status and amyloid positivity on cerebrospinal fluid (CSF) biomarkers in SMC participants. (A) Significant independent effects of $A P O E \varepsilon 4$ carrier status and cerebral amyloid status (positive or negative), but no interaction effect on CSF A $1-42$ were observed (both $P<.001$ ). Post-hoc analysis indicated a pattern of decreasing CSF level A $\beta 1-42$ by the interaction of amyloid positivity and $A P O E \varepsilon 4+$ was seen with SMC $A P O E \varepsilon 4-/ \mathrm{A} \beta$ - showing higher levels than SMC APOE $\varepsilon 4+/ \mathrm{A} \beta+, \mathrm{SMC} A P O E \varepsilon 4+/ \mathrm{A} \beta-$, and SMC APOE $\varepsilon 4-/ \mathrm{A} \beta+$, and SMC APOE $\varepsilon 4+/ \mathrm{A} \beta-$ showing higher CSF A $\beta 1-42$ levels than SMC APOE $\varepsilon 4+/ \mathrm{A} \beta+$ (all $P<.05$ ). (B) APOE $\varepsilon 4$ carrier status, but not amyloid positivity or the interaction, was significantly associated with CSF t-tau level in the SMC participants $(P=.009)$. SMC APOE $\varepsilon 4+/ \mathrm{A} \beta+$ showed higher t-tau levels than SMC APOE $\varepsilon 4-/ \mathrm{A} \beta-$ on Bonferroni-corrected post-hoc analysis $(P=.008)$. (C) Both APOE $\varepsilon 4$ carrier status and amyloid positivity were independently associated with CSF p-tau level ( $A P O E \varepsilon 4$ carrier status, $P=.014$; amyloid positivity, $P=.010$ ), but again no interaction was observed. Similar to the t-tau analyses, SMC $A P O E \varepsilon 4+/ \mathrm{A} \beta+$ had greater CSF p-tau levels than SMC APOE $\varepsilon 4-/ \mathrm{A} \beta$ - on post-hoc analysis $(P<.001)$. Abbreviations: A $\beta$, amyloid beta; EMCI, early mild cognitive impairment; $\mathrm{SMC}$, significant memory concern; $\mathrm{CN}$, cognitively normal.

is also surprising given previous findings [48,49]. However, the previously observed differences were mild and differences in methodology likely resulted in the lack of significance in the present study, despite a slight trend for decreased glucose metabolism and hippocampal volume in $\varepsilon 4+\mathrm{CN}$.

Interestingly, we observed a trend toward higher cortical glucose metabolism and larger hippocampal volume in SMC $A P O E \varepsilon 4+$, although this did not reach significance after Bonferroni-correction possibly due to the relatively small group size and attenuated power or an unknown confounding variable. Although only a nonsignificant trend, the SMC participants showed this strikingly different pattern of
$A P O E$ effects on metabolism and atrophy than $\mathrm{CN}$ or EMCI participants, suggesting that individuals with SMC may have different processes taking place than the latter groups. Further cross-sectional and longitudinal studies of changes in SCD/SMC samples are warranted to determine if these seemingly anomalous findings are of pathophysiological significance. It is noteworthy that previous studies have observed increased cortical thickness in at-risk populations, including in middle-aged APOE $\varepsilon 4$ carriers [50], CN who are transitioning to become CSF A $\beta$ positive [51], and asymptomatic PSEN1 mutation carriers before the onset of the clinical changes [52]. Furthermore, a previous study in older adults with SCD/SMC demonstrated a quadratic 
pattern of longitudinal MTL atrophy, with initial volume increases followed by decreases [22]. Future studies with longitudinal follow-up and larger samples will be important in determining the significance of this finding. If confirmed, mechanistic studies would also be indicated to determine the processes underlying these increases. In any case, this finding highlights the potential difference of SMC from $\mathrm{CN}$ participants and suggests that individuals with significant self-complaints may have a different pattern of pathology and risk than those without.

Most of the observed results provide further support of the Jack et al. model of AD biomarkers [30], suggesting that amyloid accumulation is one of the earliest measurable pathophysiological changes associated with $\mathrm{AD}$ before cognitive decline and that hypometabolic and atrophic changes primarily occur with early clinical symptoms. This study also supports the hypothesis that APOE \&4 genotype alters the hypothesized model by pushing the system in favor of early amyloid accumulation, even in cognitively normal older adults. Extension of the Jack et al. model to include an SMC stage before MCI appears warranted, as these participants represent an at-risk group. However, in contrast to the Jack et al. model, we observed an increased level of p-tau and a trend toward increased glucose metabolism and hippocampal volume in APOE $\varepsilon 4+$ SMC participants. These findings deviate from both the Jack et al. model and previous work in autosomal dominant $\mathrm{AD}$ [32] and may suggest a more complicated interaction between CSF and imaging biomarkers of neurodegeneration in the earliest stages of disease. However, given the limited detection power and significance of this finding, additional studies would be needed to fully explore this possibility. The present results also provide support for the importance of genetic variation in determining likelihood and extent of amyloid accumulation, even in preclinical stages such as SMC, which may be an important consideration for enrichment strategies for therapeutic trial enrollment based on very mildly symptomatic and/or asymptomatic patients. The availability of tau imaging using one of the newly developed tau PET ligands [53,54] could lead to further revisions in this hypothetical sequence of biomarker changes [30].

We also completed a targeted analysis within SMC participants to examine the potential for an interaction between $A P O E \quad \& 4$ carrier status and cerebral amyloid positivity determined using $\left[{ }^{18} \mathrm{~F}\right]$ Florbetapir PET. SMC participants who were both $A P O E \varepsilon 4$ carriers and amyloid positive had the most abnormal CSF amyloid and tau levels. If SMC participants were either an APOE $\varepsilon 4$ carrier or amyloid positive on $\left[{ }^{18} \mathrm{~F}\right]$ Florbetapir PET, they appeared to have intermediate levels of CSF A $\beta 1-42$, t-tau, and p-tau between those carrying both risk factors and those carrying neither risk factor. These findings suggest that although APOE $\& 4$ genotype and amyloid deposition are highly linked, these factors may have independent and/or additive effects on amyloid and tau in SMC. Furthermore, the observed reduction in CSF A $\beta 1-42$ in SMC APOE $\varepsilon 4$ carriers who were amyloid negative on $\left[{ }^{18}\right.$ F]Florbetapir PET may suggest that changes in amyloid are detectable in CSF before amyloid PET scans or that CSF $\mathrm{A} \beta$ changes are not fully reflective of amyloid aggregation.

This study has a few notable limitations. First, as previously discussed, SMC participants in the present report were recruited based on self-reported complaints of cognitive decline in the absence of informant-perceived decline. Previous studies have shown the importance of informant-based complaints in both cognitively normal and impaired populations [5]. Therefore, the evaluated SMC participants may not be fully representative of the greater population of older adults with SCD/SMC. Future studies of participants with self-based and/or informantbased complaints with longitudinal assessment of $\mathrm{AD}$ biomarkers will help to elucidate the impact of self vs. informant complaints on AD pathology and risk. Second, only a single genetic factor ( $A P O E \& 4$ carrier status) was evaluated in this study. Future studies targeting other genetic variants in SMC are warranted. Third, the present study only evaluated cross-sectional data. Studies of longitudinal outcome and rate of $\mathrm{AD}$ biomarker change may provide additional information about dynamic changes in SCD/SMC. Finally, a number of additional $\mathrm{AD}$ biomarkers were not evaluated in the present report. Future studies investigating additional imaging and CSF biomarkers may elucidate other changes occurring in SMC.

In sum, $A P O E \varepsilon 4$ positive older adults with SMC show increased cerebral amyloid, reduced CSF A $\beta 1-42$, increased CSF p-tau, and a trend for increased CSF t-tau relative to $A P O E \& 4$ noncarriers. Other $\mathrm{AD}$ biomarkers showed minimal association to $A P O E$ in SMC. Targeted analyses suggest that SMC participants who were both $A P O E$ \&4+ and positive for cerebral amyloid showed the most abnormal CSF A $\beta 1-42$, t-tau, and p-tau levels. Future longitudinal studies of dynamic processes occurring in this at-risk population will elucidate the disease vulnerability of older adults with SCD/SMC, and the impact of genetic background.

\section{Acknowledgments and Funding}

Data collection and sharing for this project was funded by the Alzheimer's Disease Neuroimaging Initiative (ADNI) (National Institutes of Health Grant U01 AG024904) and DOD ADNI (Department of Defense award number W81XWH-12-2-0012). ADNI is funded by the National Institute on Aging, the National Institute of Biomedical Imaging and Bioengineering, and through generous contributions from the following: Alzheimer's Association; Alzheimer's Drug Discovery Foundation; Araclon Biotech; BioClinica, Inc.; Biogen Idec Inc.; Bristol-Myers Squibb Company; Eisai Inc.; Elan Pharmaceuticals, Inc.; Eli Lilly and Company; EuroImmun; F. Hoffmann-La Roche Ltd and its affiliated company Genentech, Inc.; Fujirebio; GE Healthcare; IXICO Ltd.; Janssen Alzheimer Immunotherapy Research \& Development, LLC.; Johnson \& Johnson Pharmaceutical Research \& Development LLC.; Medpace, Inc.; Merck \& Co., Inc.; Meso Scale Diagnostics, LLC.; NeuroRx Research; Neurotrack Technologies; Novartis 
Pharmaceuticals Corporation; Pfizer Inc.; Piramal Imaging; Servier; Synarc Inc.; and Takeda Pharmaceutical Company. The Canadian Institutes of Health Research is providing funds to support ADNI clinical sites in Canada. Private sector contributions are facilitated by the Foundation for the National Institutes of Health (www.fnih.org). The grantee organization is the Northern California Institute for Research and Education, and the study is coordinated by the Alzheimer's Disease Cooperative Study at the University of California, San Diego. ADNI data are disseminated by the Laboratory for Neuro Imaging at the University of Southern California. ADNI was also supported by NIH grants P30 AG010129, K01 AG030514, and the Dana Foundation. Additional support for analyses included in the present report was provided by the following sources: NIA R01 AG19771 (to AJS), P30 AG10133-18S1 (to Dr. Bernardino Ghetti and AJS), National Library of Medicine (NLM) R01 LM011360 (to LS and AJS), NLM R00 LM011384 (to $\mathrm{KN}$ ), the Alzheimer's Association (New Investigator Research Grant to SLR), the Indiana University HealthIndiana University School of Medicine Strategic Research Initiative CTSI (to SLR), and P30 AG010129 (to LAB).

\section{Supplementary data}

Supplementary data related to this article can be found at http://dx.doi.org/10.1016/j.jalz.2015.03.003.

\section{RESEARCH IN CONTEXT}

1. Systematic review: To investigate our primary research question on $A P O E$ effects in significant memory concern (SMC), we searched PubMed for: "cognitive complaints (CC)," "subjective cognitive decline (SCD)," "neuroimaging," and "apolipoprotein $\mathrm{E}(A P O E)$." We then combined the returned articles to generate a summary on biomarkers in SMC/ $\mathrm{SCD} / \mathrm{CC}$ and the role of $A P O E$.

2. Interpretation: Our results provide new evidence that $A P O E$ is a major mediator of amyloid and tau abnormalities in SMC, suggesting that these abnormalities occur before cognitive symptoms in this population. However, metabolism and atrophy were not affected, suggesting that these may be linked to cognitive decline.

3. Future directions: To confirm the current findings, additional analyses with larger and more diverse samples and longitudinal studies would be beneficial. Additional Alzheimer's disease biomarkers not evaluated in the present report may also elucidate the pathophysiological processes occurring in SMC participants. Finally, the assessment of the impact of other genetic variants beyond $A P O E$ would expand this work.

\section{References}

[1] Alzheimer's Association. 2014 Alzheimer's disease facts and figures. Alzheimers Dement 2014;10:e47-92.

[2] Sperling RA, Aisen PS, Beckett LA, Bennett DA, Craft S, Fagan AM, et al. Toward defining the preclinical stages of Alzheimer's disease: recommendations from the National Institute on Aging-Alzheimer's Association workgroups on diagnostic guidelines for Alzheimer's disease. Alzheimers Dement 2011;7:280-92.

[3] Jessen F, Amariglio RE, van Boxtel M, Breteler M, Ceccaldi M, Chetelat G, et al. A conceptual framework for research on subjective cognitive decline in preclinical Alzheimer's disease. Alzheimers Dement 2014;10:844-52.

[4] Saykin AJ, Wishart HA, Rabin LA, Santulli RB, Flashman LA, West JD, et al. Older adults with cognitive complaints show brain atrophy similar to that of amnestic MCI. Neurology 2006;67:834-42.

[5] Caselli RJ, Chen K, Locke DE, Lee W, Roontiva A, Bandy D, et al. Subjective cognitive decline: self and informant comparisons. Alzheimers Dement 2014;10:93-8.

[6] Gallassi R, Oppi F, Poda R, Scortichini S, Stanzani Maserati M, Marano G, et al. Are subjective cognitive complaints a risk factor for dementia? Neurol Sci 2010;31:327-36.

[7] Gifford KA, Liu D, Lu Z, Tripodis Y, Cantwell NG, Palmisano J, et al. The source of cognitive complaints predicts diagnostic conversion differentially among nondemented older adults. Alzheimers Dement 2013;10:319-27.

[8] Glodzik-Sobanska L, Reisberg B, De Santi S, Babb JS, Pirraglia E, Rich KE, et al. Subjective memory complaints: presence, severity and future outcome in normal older subjects. Dement Geriatr Cogn Disord 2007;24:177-84.

[9] Hohman TJ, Beason-Held LL, Lamar M, Resnick SM. Subjective cognitive complaints and longitudinal changes in memory and brain function. Neuropsychology 2011;25:125-30.

[10] Jessen F, Wiese B, Bachmann C, Eifflaender-Gorfer S, Haller F, Kolsch H, et al. Prediction of dementia by subjective memory impairment: effects of severity and temporal association with cognitive impairment. Arch Gen Psychiatry 2010;67:414-22.

[11] Jessen F, Wolfsgruber S, Wiese B, Bickel H, Mosch E, Kaduszkiewicz $\mathrm{H}$, et al. $\mathrm{AD}$ dementia risk in late $\mathrm{MCI}$, in early $\mathrm{MCI}$, and in subjective memory impairment. Alzheimers Dement 2014; 10:76-83.

[12] Jonker C, Geerlings MI, Schmand B. Are memory complaints predictive for dementia? A review of clinical and population-based studies. Int J Geriatr Psychiatry 2000;15:983-91.

[13] Nunes T, Fragata I, Ribeiro F, Palma T, Maroco J, Cannas J, et al. The outcome of elderly patients with cognitive complaints but normal neuropsychological tests. J Alzheimers Dis 2010;19:137-45.

[14] Ramakers IH, Visser PJ, Aalten P, Boesten JH, Metsemakers JF, Jolles J, et al. Symptoms of preclinical dementia in general practice up to five years before dementia diagnosis. Dement Geriatr Cogn Disord 2007;24:300-6.

[15] Reid LM, Maclullich AM. Subjective memory complaints and cognitive impairment in older people. Dement Geriatr Cogn Disord 2006; 22:471-85.

[16] Reisberg B, Shulman MB, Torossian C, Leng L, Zhu W. Outcome over seven years of healthy adults with and without subjective cognitive impairment. Alzheimers Dement 2010;6:11-24.

[17] Chao LL, Mueller SG, Buckley ST, Peek K, Raptentsetseng S, Elman J, et al. Evidence of neurodegeneration in brains of older adults who do not yet fulfill MCI criteria. Neurobiol Aging 2010;31:368-77.

[18] Erk S, Spottke A, Meisen A, Wagner M, Walter H, Jessen F. Evidence of neuronal compensation during episodic memory in subjective memory impairment. Arch Gen Psychiatry 2011;68:845-52.

[19] Jessen F, Feyen L, Freymann K, Tepest R, Maier W, Heun R, et al. Volume reduction of the entorhinal cortex in subjective memory impairment. Neurobiol Aging 2006;27:1751-6. 
[20] Rodda J, Dannhauser T, Cutinha DJ, Shergill SS, Walker Z. Subjective cognitive impairment: functional MRI during a divided attention task. Eur Psychiatry 2011;26:457-62.

[21] Scheef L, Spottke A, Daerr M, Joe A, Striepens N, Kolsch H, et al. Glucose metabolism, gray matter structure, and memory decline in subjective memory impairment. Neurology 2012;79:1332-9.

[22] Stewart R, Godin O, Crivello F, Maillard P, Mazoyer B, Tzourio C, et al. Longitudinal neuroimaging correlates of subjective memory impairment: 4-year prospective community study. Br J Psychiatry 2011;198:199-205.

[23] Striepens N, Scheef L, Wind A, Meiberth D, Popp J, Spottke A, et al. Interaction effects of subjective memory impairment and ApoE4 genotype on episodic memory and hippocampal volume. Psychol Med 2011;41:1997-2006.

[24] Visser PJ, Verhey F, Knol DL, Scheltens P, Wahlund LO, FreundLevi Y, et al. Prevalence and prognostic value of CSF markers of Alzheimer's disease pathology in patients with subjective cognitive impairment or mild cognitive impairment in the DESCRIPA study: a prospective cohort study. Lancet Neurol 2009;8:619-27.

[25] Wang Y, Risacher SL, West JD, McDonald BC, Magee TR, Farlow MR, et al. Altered default mode network connectivity in older adults with cognitive complaints and amnestic mild cognitive impairment. J Alzheimers Dis 2013;35:751-60.

[26] Wang Y, West JD, Flashman LA, Wishart HA, Santulli RB, Rabin LA, et al. Selective changes in white matter integrity in MCI and older adults with cognitive complaints. Biochim Biophys Acta 2012; 1822:423-30.

[27] Barnes LL, Schneider JA, Boyle PA, Bienias JL, Bennett DA. Memory complaints are related to Alzheimer disease pathology in older persons. Neurology 2006;67:1581-5.

[28] Mosconi L, De Santi S, Brys M, Tsui WH, Pirraglia E, GlodzikSobanska L, et al. Hypometabolism and altered cerebrospinal fluid markers in normal apolipoprotein E E4 carriers with subjective memory complaints. Biol Psychiatry 2008;63:609-18.

[29] Rowe CC, Ellis KA, Rimajova M, Bourgeat P, Pike KE, Jones G, et al. Amyloid imaging results from the Australian Imaging, Biomarkers and Lifestyle (AIBL) study of aging. Neurobiol Aging 2010; 31:1275-83.

[30] Jack CR Jr, Knopman DS, Jagust WJ, Petersen RC, Weiner MW, Aisen PS, et al. Tracking pathophysiological processes in Alzheimer's disease: an updated hypothetical model of dynamic biomarkers. Lancet Neurol 2013;12:207-16.

[31] Risacher SL, Kim S, Shen L, Nho K, Foroud T, Green RC, et al. The role of apolipoprotein E (APOE) genotype in early mild cognitive impairment (E-MCI). Front Aging Neurosci 2013;5:11.

[32] Bateman RJ, Xiong C, Benzinger TL, Fagan AM, Goate A, Fox NC, et al. Clinical and biomarker changes in dominantly inherited Alzheimer's disease. N Engl J Med 2012;367:795-804.

[33] Jack CR Jr, Bernstein MA, Borowski BJ, Gunter JL, Fox NC, Thompson PM, et al. Update on the magnetic resonance imaging core of the Alzheimer's Disease Neuroimaging Initiative. Alzheimers Dement 2010;6:212-20.

[34] Jagust WJ, Bandy D, Chen K, Foster NL, Landau SM, Mathis CA, et al. The Alzheimer's Disease Neuroimaging Initiative positron emission tomography core. Alzheimers Dement 2010;6:221-9.

[35] Trojanowski JQ, Vandeerstichele H, Korecka M, Clark CM, Aisen PS, Petersen RC, et al. Update on the biomarker core of the Alzheimer's Disease Neuroimaging Initiative subjects. Alzheimers Dement 2010; 6:230-8.

[36] Petersen RC, Aisen PS, Beckett LA, Donohue MC, Gamst AC, Harvey DJ, et al. Alzheimer's Disease Neuroimaging Initiative (ADNI): clinical characterization. Neurology 2010;74:201-9.
[37] Saykin AJ, Shen L, Foroud TM, Potkin SG, Swaminathan S, Kim S, et al. Alzheimer's Disease Neuroimaging Initiative biomarkers as quantitative phenotypes: Genetics core aims, progress, and plans. Alzheimers Dement 2010;6:265-73.

[38] Weiner MW, Aisen PS, Jack CR Jr, Jagust WJ, Trojanowski JQ, Shaw L, et al. The Alzheimer's Disease Neuroimaging Initiative: progress report and future plans. Alzheimers Dement 2010;6:202-2117.

[39] Brett M, Anton JL, Valabregue R, Poline J-B. Region of interest analysis using an SPM toolbox [abstract]. Presented at the 8th international conference on functional mapping of the human brain, June 2-6, 2002. Sendai, Japan 2002.

[40] Jack CR Jr, Bernstein MA, Fox NC, Thompson P, Alexander G, Harvey D, et al. The Alzheimer's Disease Neuroimaging Initiative (ADNI): MRI methods. J Magn Reson Imaging 2008;27:685-91.

[41] Dale A, Fischl B, Sereno M. Cortical surface-based analysis. I. Segmentation and surface reconstruction. Neuroimage 1999;9:179-94.

[42] Fischl B, Sereno M, Dale A. Cortical surface-based analysis. II: inflation, flattening, and a surface-based coordinate system. Neuroimage 1999;9:195-207.

[43] Shaw LM, Vanderstichele H, Knapik-Czajka M, Figurski M, Coart E, Blennow K, et al. Qualification of the analytical and clinical performance of CSF biomarker analyses in ADNI. Acta Neuropathol 2011;121:597-609.

[44] Shaw LM, Vanderstichele H, Knapik-Czajka M, Clark CM, Aisen PS, Petersen RC, et al. Cerebrospinal fluid biomarker signature in Alzheimer's disease Neuroimaging Initiative subjects. Ann Neurol 2009;65:403-13.

[45] Landau SM, Breault C, Joshi AD, Pontecorvo M, Mathis CA, Jagust WJ, et al. Amyloid-beta imaging with Pittsburgh compound $\mathrm{B}$ and florbetapir: comparing radiotracers and quantification methods. J Nucl Med 2013;54:70-7.

[46] Smith CD, Andersen AH, Gold BT. Structural brain alterations before mild cognitive impairment in ADNI: validation of volume loss in a predefined antero-temporal region. J Alzheimers Dis 2012;31(Suppl 3):S49-58.

[47] Striepens N, Scheef L, Wind A, Popp J, Spottke A, CooperMahkorn D, et al. Volume loss of the medial temporal lobe structures in subjective memory impairment. Dement Geriatr Cogn Disord 2010; 29:75-81.

[48] Jagust WJ, Landau SM, Alzheimer's Disease Neuroimaging I. Apolipoprotein E, not fibrillar beta-amyloid, reduces cerebral glucose metabolism in normal aging. J Neurosci 2012;32:18227-33.

[49] Wishart HA, Saykin AJ, McAllister TW, Rabin LA, McDonald BC, Flashman LA, et al. Regional brain atrophy in cognitively intact adults with a single APOE epsilon4 allele. Neurology 2006;67:1221-4.

[50] Espeseth T, Westlye LT, Fjell AM, Walhovd KB, Rootwelt H, Reinvang I. Accelerated age-related cortical thinning in healthy carriers of apolipoprotein E epsilon 4. Neurobiol Aging 2008;29:329-40.

[51] Fortea J, Sala-Llonch R, Bartres-Faz D, Llado A, Sole-Padulles C, Bosch B, et al. Cognitively preserved subjects with transitional cerebrospinal fluid ss-amyloid 1-42 values have thicker cortex in Alzheimer's disease vulnerable areas. Biol Psychiatry 2011;70:183-90.

[52] Fortea J, Sala-Llonch R, Bartres-Faz D, Bosch B, Llado A, Bargallo N, et al. Increased cortical thickness and caudate volume precede atrophy in PSEN1 mutation carriers. J Alzheimers Dis 2010;22:909-22.

[53] Chien DT, Szardenings AK, Bahri S, Walsh JC, Mu F, Xia C, et al. Early clinical PET imaging results with the novel PHF-tau radioligand [F18]-T808. J Alzheimers Dis 2014;38:171-84.

[54] Maruyama M, Shimada H, Suhara T, Shinotoh H, Ji B, Maeda J, et al. Imaging of tau pathology in a tauopathy mouse model and in Alzheimer patients compared to normal controls. Neuron 2013; 79:1094-108. 